\title{
PROCESSOS FORMATIVOS NAS \\ LICENCIATURAS: DESAFIOS DA E NA \\ DOCÊNCIA
}

\author{
TRAINING PROCESSES IN TEACHING DEGREE: CHALLENGES \\ OF AND IN TEACHING
}

\section{PROCESOS FORMATIVOS EN LOS CURSOS DE PROFESORADO: DESAFÍOS DE LA YEN LA DOCENCIA}

\author{
Doris Pires Vargas Bolzan ${ }^{1}$ \\ Universidade Federal de Santa Maria, Professora do Programa de Pós-graduação em \\ Educação e do Departamento de Metodologia do Ensino
}

Ana Carla Hollweg Powaczuk ${ }^{2}$

Universidade Federal de Santa Maria, Professora do Departamento de Metodologia do Ensino

Resumo: Neste artigo discutimos a respeito da formação de professores na educação superior a partir da compreensão dos processos formativos que propiciam sua dinâmica. O estudo desenvolveu-se a partir da abordagem qualitativo-narrativa, de cunho sociocultural; foi realizado com professores e estudantes das licenciaturas de uma universidade pública e de uma instituição de ensino superior comunitária do interior do Rio Grande do Sul. O objetivo foi compreender as concepções sobre aprendizagem docente de professores em formação inicial e de formadores, e como essas concepções implicam os processos formativos da docência. Consideramos que os trajetos formativos assumidos representam o modo com o qual o perfil profissional vai se desenhando e como as vivências formativas emergem diante do desafio de (re)contextualizar a profissão.

Palavras-chave: Processos formativos. Formação inicial. Professores/formadores. Educação superior. Aprendizagem docente.

\footnotetext{
${ }^{1}$ Doutora e Mestre em Educação pela Universidade Federal do Rio Grande do Sul.

${ }^{2}$ Doutora e Mestre em Educação pela Universidade Federal de Santa Maria.
} 
Abstract: In this article we discuss about teacher training in higher education from the understanding of the training processes which provide its dynamics. The study was developed from a narrative qualitative approach, as a sociocultural initiative performed by teachers and students of graduation courses from a public university and a community higher education institution in the country area of Rio Grande do Sul. Our objective was to understand the conceptions about teacher learning of teachers in their initial education and also teacher trainers, and how these conceptions imply in training processes of teachers. We understood that the formative paths can represent the way a professional profile is built and how formative experiences emerge in the light of the challenge of recontextualise the profession.

Keywords: Training processes. Initial education. Teachers/teacher trainers. Higher education. Teacher learning.

Resumen: En este artículo discutimos acerca de la formación de profesores en la educación superior a partir de los procesos formativos que propician su dinámica. El estudio lo desarrollamos mediante el abordaje cualitativo narrativo, de carácter sociocultural, con profesores y estudiantes de los cursos de profesorado, de una universidad pública y de una institución de enseñanza superior comunitaria del interior de Rio Grande do Sul. El objetivo es comprender cuáles las concepciones sobre aprendizaje docente de profesores en formación inicial y de formadores y cómo ellas implican los procesos formativos del docente. Consideramos que los trayectos formativos asumidos representan el modo como se va diseñando el perfil profesional y cómo las vivencias formativas emergen ante el desafio de (re)contextualizar la profesión.

Palabras clave: Procesos formativos. Formación inicial. Profesores/formadores. Educación superior. Aprendizaje docente.

\section{INTRODUZINDO A TEMÁTICA}

Neste texto problematizamos os desafios da formação de professores na educação superior a partir da compreensão dos processos formativos que propiciam sua dinâmica. Apresentamos achados teóricos e investigativos da pesquisa guarda-chuva que viemos desenvolvendo no último triênio que trata da formação de formadores e da formação inicial para a docência nas licenciaturas. O estudo desenvolveu-se a partir de uma abordagem qualitativo-narrativa, de cunho sociocultural, realizada com professores e estudantes de cursos de licenciatura de uma universidade pública e de uma instituição de ensino superior comunitária do interior do Estado do 
Rio Grande do Sul. O objetivo com o estudo foi compreender as concepções sobre aprendizagem docente de estudantes professores em formação inicial e de professores formadores das licenciaturas, e, ainda, como essas concepções implicam os processos formativos da docência.

Entre os tantos desafios encontrados em nossos estudos e pesquisas está a possibilidade de refletirmos sobre as dinâmicas formativas em andamento em espaços de formação, enfocando a aprendizagem de ser professor tanto para formadores quanto para professores em formação inicial. Consideramos que o percurso docente-discente assumido e dinamizado pode representar o modo com o qual o perfil profissional vai ser desenhado e como as vivências formativas emergem diante do desafio de contextualizar e recontextualizar a profissão, o que poderá favorecer a conscientização da docência como profissão e o seu consequente desenvolvimento na carreira.

Os conceitos explorados a partir deste estudo evidenciam que a cultura de colaboração em espaços institucionais pode favorecer os professores formadores e os estudantes professores em formação inicial a refletir, compartilharem e reconstruírem experiências e conhecimentos próprios à especificidade da docência, seja na educação básica, seja na superior, favorecendo o desenvolvimento profissional docente.

\section{A TESSITURA DOS CONCEITOS: PERCURSOS DE PESQUISA}

Na pesquisa intitulada Aprendizagem da docência: processos formativos de estudantes e formadores da educação superior teve-se como foco aprofundar a compreensão relativa às concepções sobre aprendizagem docente dos estudantes professores em formação inicial e professores formadores das licenciaturas, e como estas implicam os processos formativos para a docência. É um estudo interinstitucional e integrado que envolveu professores e estudantes da educação superior, inicialmente das licenciaturas em Pedagogia e em Educação Especial (diurno e noturno) de uma universidade pública e de uma instituição de ensino superior comunitária.

Acreditamos que via rede de interações e mediações colaborativas e compartilhadas é possível promover o processo de aprender a ser professor. Tal processo organiza-se a partir de movimentos desencadeados e entrelaçados pela trajetória pessoal e profissional dos sujeitos neles envolvidos, considerando-se a cultura institucional dos contextos formativos. Compreendemos a cultura institucional como um conjunto de ideias, crenças, teorias, normas, valores, ideologias e dimensões correlatas que interagem com o conhecimento e com a prática pedagógica que se produz na escola e nos espaços acadêmicos. Constitui-se por esquemas subjetivos (relativos aos 
componentes práticos, cognitivos e dinâmicos das ações) e por todas as elaborações construídas pelos indivíduos em torno desses componentes (SACRISTÁN, 1997). Implica a coexistência de concepções, interesses e práticas diferentes, nem sempre explicitadas e refletidas, expressas pelo reconhecimento de traços históricos e sociais nas instituições (CUNHA, 2006).

Nessa direção, a cultura de colaboração emerge como elemento a ser destacado e valorizado na constituição de uma ambiência institucional. De acordo com Vaillant e Marcelo (2012), a perspectiva de um modelo de ressonância colaborativa caracteriza-se como um processo no qual sua principal característica está assentada na ideia de aprendizagem ao longo da vida, destacando-se como fundamento principal a possibilidade de aprender permanentemente em contextos múltiplos e diversos. As chaves desse processo encontram-se na constituição de uma cultura de colaboração produzida em torno de um projeto coletivo, no qual os professores formadores e em formação podem se envolver. Esse espaço precisa converter-se em um lugar "[...] onde se indaga, de forma sistemática e crítica, sobre o ensino, a aprendizagem e a escola [e/ou Instituições de ensino superior] como organização." (VAILLANT; MARCELO, 2012, p. 95). O elemento diferencial está em se produzir redes de relações capazes de promover a interdependência entre os sujeitos. Equivale a dizer que não há submissão de um sobre o outro, mas o intercâmbio e a reciprocidade das relações, bem como a reflexão sobre o inacabamento. Logo, o trabalho sistemático com as incertezas e dúvidas é assumido como inerente ao processo de aprender o exercício da docência e como fonte de experimentação de novas práticas, seja na escola, seja em outros espaços formativos, acadêmicos ou não, permitindo que tais lugares se tornem nichos de aprendizagem.

Assim, entendemos a aprendizagem docente como um processo que implica o domínio de conhecimentos, saberes e fazeres de determinado campo, além da sensibilidade do docente como pessoa e profissional em termos de atitude e valores, tendo a reflexão como componente intrínseco ao processo de ensinar, de aprender, de formar-se e, consequentemente, de desenvolver-se profissionalmente. Não é possível se falar em um aprender generalizado a ser professor, mas, sim, trata-se de entendê-lo no contexto concreto de cada sujeito, considerando suas trajetórias de formação e para qual atividade formativa estão direcionadas (BOLZAN, 2002, 2008, 2009a, 2009b, 2012a, 2012b, 2013, 2014; BOLZAN; ISAIA, 2006, 2007, 2010).

Desse modo, o processo de reflexão crítica, feito individualmente ou em grupo, pode tornar conscientes os modelos teóricos e epistemológicos que se evidenciam nos processos formativos e, ao mesmo tempo, favorecer a compreensão da 
aprendizagem de ser professor. Acreditamos, pois, que obteremos um avanço sobre questões pedagógicas, à medida que busquemos compreender as relações recíprocas entre o domínio do saber (conhecimento científico) e o domínio do saber fazer (conhecimento prático). Logo, o processo de pensamento e as formas de conceber e de desenvolver o ensino explicitam como o sistema de concepções pessoais se desdobra e se organiza para professores e estudantes (BOLZAN, 2002, 2012b, 2013, 2014, 2015).

Nossos estudos que tratam da aprendizagem docente e dos processos formativos nos permitem inferir que os ciclos de vida profissional docente são tecidos pelos fios das concepções de docência que os professores paulatinamente constroem, aliados a um processo contínuo de aprendizagem.

Articuladas a este estudo desenvolvemos parcerias com pesquisadores da área que têm colaborado para adensar as discussões acerca dos contornos dos campos formativos, tratando das especificidades nas diferentes áreas de conhecimento e sua influência na atuação docente dos professores universitários e os movimentos que dele decorrem, indicando que as interconexões entre ambientes formativos presenciais e virtuais serão a tônica desta década (ISAIA, 2012-2015; DA ROCHA, 2013-2015).

Os resultados destes estudos têm permitido constatar que há diferentes modos de aprender a ser professor, uma vez que a docência é um processo dinâmico e complexo. Assim, acreditamos que estudantes professores em formação inicial e professores formadores vivenciam variadas experiências formativas; entretanto, não sabemos como essa formação ocorre em suas atividades, nem mesmo como essas atividades implicam/repercutem esse ideário de formação.

Nessa direção, nossa questão orientadora do estudo é: que concepções sobre aprendizagem docente manifestam os estudantes e professores formadores das licenciaturas e como estas implicam os processos formativos da docência?

O estudo qualitativo-narrativo foi desenvolvido por meio de entrevistas semiestruturadas com os estudantes professores em formação inicial e os professores formadores dos Cursos de Pedagogia e Educação Especial de uma instituição universitária do interior do Rio Grande do Sul e do Curso de Pedagogia de uma instituição de ensino superior comunitária (cinco cursos).

A pesquisa foi desenvolvida em três etapas: na primeira, realizamos um estudo exploratório, examinando os currículos lattes dos professores formadores, bem como dedicamo-nos ao estudo dos projetos político-pedagógicos, destacando-se a dinâmica das matrizes curriculares dos cursos em estudo, a fim de desenharmos um panorama dos espaços formativos e seus atores; na segunda etapa, levantamos as ideias 
que os sujeitos colaboradores do estudo (professores formadores e estudantes professores em formação inicial dos diversos semestres dos cursos) constroem acerca de sua aprendizagem docente e como os processos formativos em andamento repercutem nas concepções de aprendizagem da docência narradas; identificamos as recorrências que caracterizam os elementos constituintes das categorias e as dimensões de análise a serem adotados; na terceira e última etapa, buscamos explicitar a repercussão dos conhecimentos e saberes apropriados na aprendizagem docente a partir das atividades de estudos desenvolvidas pelos sujeitos da investigação.

Pautamos a investigação na abordagem qualitativo-narrativa de cunho sociocultural, a qual centra sua atenção nos processos de construção pessoal e profissional; referimo-nos a todo o conjunto das narrativas colhido nas entrevistas narrativas com professores formadores e estudantes professores em formação inicial. Por meio da análise das narrativas desses participantes, acreditamos ser possível fazer a leitura dos significados de suas atividades, revelando a subjetividade e a objetividade das relações, tendo sua ênfase mais na singularidade dos fatos do que na sua generalização.

Narrar fatos ou situações pressupõe a consideração de três aspectos essenciais: a interpretação dos sentidos, a socialização da significação e a práxis, que originam a redescoberta do conhecimento como construção, isto é, o acesso ao conhecimento com autoria, a partir de processos interativos e mediacionais estabelecidos. Assim, a função interpretativa dos sentidos de uma narrativa, no que diz respeito à formação, decorre dos conhecimentos e saberes inseparáveis de sua vivência pessoal, de sua experiência acadêmica e dos processos formativos experimentados (CONNELLY; CLANDININ, 1995; SARMENTO, 1994).

Para esses autores, a função socializadora da significação consiste no fato de traduzirmos um espaço dialógico intersubjetivo a partir dos múltiplos sentidos e significados construídos coletivamente, mesmo que sejam interpretados de forma marcadamente individual. Logo, a função da práxis diz respeito à relação entre as duas primeiras, isto é, assenta-se na intersubjetividade dos sentidos e na transformação do que existe como verdadeiro, possibilitando a reorganização da ação.

Desse modo, a partir da utilização de narrativas na interpretação e compreensão dos fatos, situações e/ou histórias de professores, precisamos considerar os seguintes aspectos: as narrativas não são necessariamente articuladas e unívocas, podem ser parciais e incoerentes, o que torna indispensável realizar um esforço de articulação com os conhecimentos subentendidos de onde elas provêm, permitindo, assim, preencher as lacunas ou elementos ambíguos que surgirem; torna-se também essencial conhecer o contexto no qual se contam os fatos e situações, para compreen- 
der seu sentido e significado; a narrativa tem uma configuração performática, ou seja, à medida que "[...] incide sobre o mundo, interpretando-o, age sobre quem a escuta, possibilitando nesse vaivém entre contar e ouvir, o contador, a audiência e a própria história sofrerem transformações.” (SARMENTO, 1994, p. 125).

A compreensão e a interpretação das narrativas, a partir dessas dimensões, exigem uma espécie de estudo da contextura na qual acontece a atividade discursiva/ narrativa, destacando-se a atenção e a eloquência utilizadas pelos narradores. Consideramos que compreender o modo como se apresenta o tecido organizacional do curso implica explicitar suas características e peculiaridades, colocando-se em evidência o contexto de cada um. Acreditamos que a contextura é a chave para a construção de uma análise na qual se pode reconhecer a forma com que se entrelaçam e prendem os fios da trama formativa, buscando responder aos objetivos do estudo. Nosso esforço nessa busca levou-nos ao detalhamento dos elementos que constituem o universo dos cursos em análise.

\section{A CONTEXTURA DA INVESTIGAÇÃO}

$\mathrm{Na}$ contextura da investigação dedicamo-nos ao estudo dos projetos político-pedagógicos (PPPs), bem como do currículo lattes dos professores formadores. $\mathrm{O}$ exame dos PPPs dos cursos de licenciatura das duas Instituições de Ensino Superior (IES) pesquisadas nos proporcionou compreender os princípios orientadores que caracterizam e movimentam os currículos dos cursos pesquisados, reconhecendo suas particularidades organizacionais, ainda que tenham as diretrizes como elemento orientador comum.

Evidenciamos a intencionalidade dos cursos participantes em articular a formação inicial do professor ao ensino, à pesquisa e à extensão, objetivando a formação de um profissional a partir das demandas da contemporaneidade. Esse aspecto conduziu-nos à análise acerca da repercussão dessas articulações das matrizes curriculares dos cursos no processo de aprendizagem da docência dos professores formadores e estudantes.

O perfil dos egressos indicou a intenção do curso quanto às características que pretende que os estudantes desenvolvam, a fim de corresponder às demandas identificadas no campo profissional. Nos Cursos de Pedagogia de ambas as IES, há destaque para o perfil generalista atribuído à formação inicial do pedagogo, de modo a contemplar o que está disposto nas Diretrizes Curriculares Nacionais para a formação de professores e, em especial, nas diretrizes para a formação do Pedagogo. 
No Curso de Educação Especial há uma ênfase em relação às habilidades a serem desenvolvidas pelo estudante ao longo da formação para a identificação das necessidades educacionais especiais dos estudantes e definição e implementação de estratégias para a flexibilização, e à integralização curricular, assim como à adaptação de procedimentos didático-pedagógicos para o público da Educação Especial.

Nessa perspectiva, evidenciamos diferenciações nos cursos investigados, considerando o foco a que se destina a formação, o perfil organizacional da instituição, bem como as estratégias pedagógicas relativas à concretização da matriz curricular estabelecida. Essa situação evidencia a relação singular que se estabelece nas organizações curriculares das diferentes licenciaturas, denotando a importância de compreendermos os processos que perfazem a configuração curricular, considerando sua dinâmica institucional e os sujeitos que a colocam em movimento.

Nessa direção, o estudo exploratório relativo aos docentes dos cursos contemplou a análise dos currículos lattes dos professores atuantes nos diferentes semestres, sendo 39 docentes/colaboradores. Como critérios de escolha dos sujeitos/ colaboradores da pesquisa elegemos, prioritariamente, aqueles com inserção nos colegiados dos cinco cursos e/ou integrantes do Núcleo Docente Estruturante (NDE), pertencentes a cada um dos quatro departamentos didáticos, no caso da IES pública, e os professores formadores vinculados diretamente ao curso na IES comunitária, que não conta com departamentos.

$\mathrm{O}$ estudo dessas fontes permitiu-nos reconhecer os níveis e áreas de formação, além de conhecer as trajetórias formativas e, assim, colocar em evidência os espaços e áreas do conhecimento em que vem ocorrendo a formação dos professores formadores. O tempo de serviço também foi um dado levantado, o que nos permitiu conhecer a experiência pregressa dos sujeitos na instituição que atuam e as experiências anteriores ao ingresso na atual carreira na educação universitária. Ainda quanto ao tempo de serviço, distribuímos o grupo de docentes conforme a etapa na carreira em iniciante, intermediário e final.

Do conjunto dos 39 professores, 15 encontram-se na fase inicial da carreira, com até cinco anos de atuação em uma IES pública; identificamos que muitos destes já tinham uma trajetória em IES privada ou comunitária. ${ }^{33}$

Do total de docentes formadores, oito estão na fase intermediária na IES pública, e quatro, na IES comunitária. Na IES pública cinco estão na fase final da

\footnotetext{
${ }^{3}$ Como desdobramento dessa temática estamos aprofundando as discussões acerca da iniciação à carreira docente na Universidade Pública, a partir de um estudo de estágio pós-doutoral, intitulado A tessitura da docência universitária de professores iniciantes: movimentos da professoralidade (POWACZUK, 2014).
} 
carreira, e não há nenhum docente, nessa mesma fase, na IES comunitária. Todos os docentes formadores, da IES pública ou comunitária, estão envolvidos em atividade de pesquisa e extensão, mas um número reduzido deles (10) está envolvido na pós-graduação, o que representa menos de $30 \%$ de docentes.

O mapeamento das experiências pregressas dos professores nos diferentes níveis de ensino permitiu-nos reconhecer que as diferentes trajetórias são marcadas por envolvimento com a pesquisa, a gestão, a extensão e a docência na educação básica. Esse levantamento sinalizou a necessidade de maior aprofundamento acerca desses dados, a fim de reconhecermos a articulação existente entre ensino, pesquisa e extensão experienciados pelos docentes e a repercussão dessas trajetórias em outros níveis de ensino.

Com os dados mapeados a partir da análise dos PPPs e dos currículos lattes dos professores, iniciamos a elaboração dos tópicos-guias que serviram para as entrevistas narrativas realizadas. Os tópicos dizem respeito:

a) à trajetória formativa e profissional dos professores formadores, que indica os trajetos adotados desde a formação inicial até a titulação de doutor que os habilitou a ingressarem em uma Instituição de Educação Superior, possibilitando-nos compreender quem é esse formador e que usos fazem dessa trajetória na construção da sua própria docência; no caso dos estudantes professores em formação inicial, reconhecemos a importância de apreender como ocorreu o processo de escolha pela licenciatura, mais especificamente como aconteceu a opção pela docência e quais impactos tiveram suas vivências como estudantes na educação básica;

b) à formação inicial dos docentes, que implica conhecer os desafios da formação para os professores formadores, bem como identificar as exigências inerentes às escolhas profissionais e os modos de definição dos percursos adotados, destacando-se como os processos de aprendizagem foram se consolidando, por meio da compreensão dos processos de ensinar expressos nas dinâmicas de sala de aula; em relação aos estudantes professores em formação inicial destacamos, especialmente, a inserção na docência na educação básica e suas repercussões nos processos formativos em andamento; 
c) às concepções sobre a docência, o que implica identificar como elas são expressas pelos sujeitos a partir da compreensão dos processos organizacionais dos cursos, ou seja, entender quais estratégias são adotadas e como a dinâmica pedagógica se estabelece, evidenciando os processos avaliativos implementados. Essa relação está presente nas atividades formativas explicitadas nas matrizes curriculares, definidas pelas cargas horárias, que são distribuídas em atividades teóricas e atividades práticas, muitas vezes, expressas por diferentes componentes curriculares. Nesse âmbito, o envolvimento nas atividades de ensino, pesquisa e extensão pode ser um elemento que amplia as experiências formativas e proporciona a compreensão dessas relações tanto para professores formadores quanto para estudantes professores em formação inicial.

A partir desses tópicos-guias as entrevistas foram realizadas com os sujeitos colaboradores do nosso estudo. Foram entrevistados 35 estudantes professores em formação inicial dos 42 que se dispuseram a participar, nos cinco cursos pesquisados.

No que se refere aos professores formadores, contamos com a colaboração de 39 do conjunto de 42 que aceitaram participar do estudo.

Do Curso de Educação Especial (diurno - IES pública) foram entrevistados seis acadêmicos dos $3^{\circ}, 5^{\circ}$ e $7^{\circ}$ semestres. Do Curso de Educação Especial (noturno IES pública) foram entrevistados sete acadêmicos dos $2^{\circ}, 4^{\circ}, 6^{\circ}$ e $8^{\circ}$ semestres.

No Curso de Pedagogia (noturno - IES pública) foram entrevistados oito acadêmicos dos $4^{\circ}, 6^{\circ}, 8^{\circ}$ e $10^{\circ}$ semestres. Já no Curso de Pedagogia (diurno - IES pública) foram entrevistados seis acadêmicos dos $3^{\circ}, 5^{\circ}$ e $7^{\circ}$ semestres. Na IES comunitária, ainda, no Curso de Pedagogia (noturno) foram entrevistados oito acadêmicos $\operatorname{dos} 3^{\circ}, 5^{\circ}, 7^{\circ}$ e $8^{\circ}$ semestres.

Para a análise, realizamos, primeiramente, o estudo preliminar de um conjunto de narrativas, destacando os elementos recorrentes expressos pelos professores e estudantes em formação inicial. As recorrências iniciais foram sendo orientadoras da problematização nessa fase preliminar, desafiando-nos a identificar as singularidades e as aproximações possíveis de serem feitas a partir das vozes/ditos dos sujeitos colaboradores do estudo. A cada emergência fomos desafiados a reorganizar os dados preliminares de modo a compor as categorias do estudo. Assim, apresentamos o esquema resultante da exploração do conjunto de narrativas, o que permitiu a configuração das categorias de análise e suas dimensões expressas. 
Esquema 1 - Síntese da dinâmica analítica da investigação

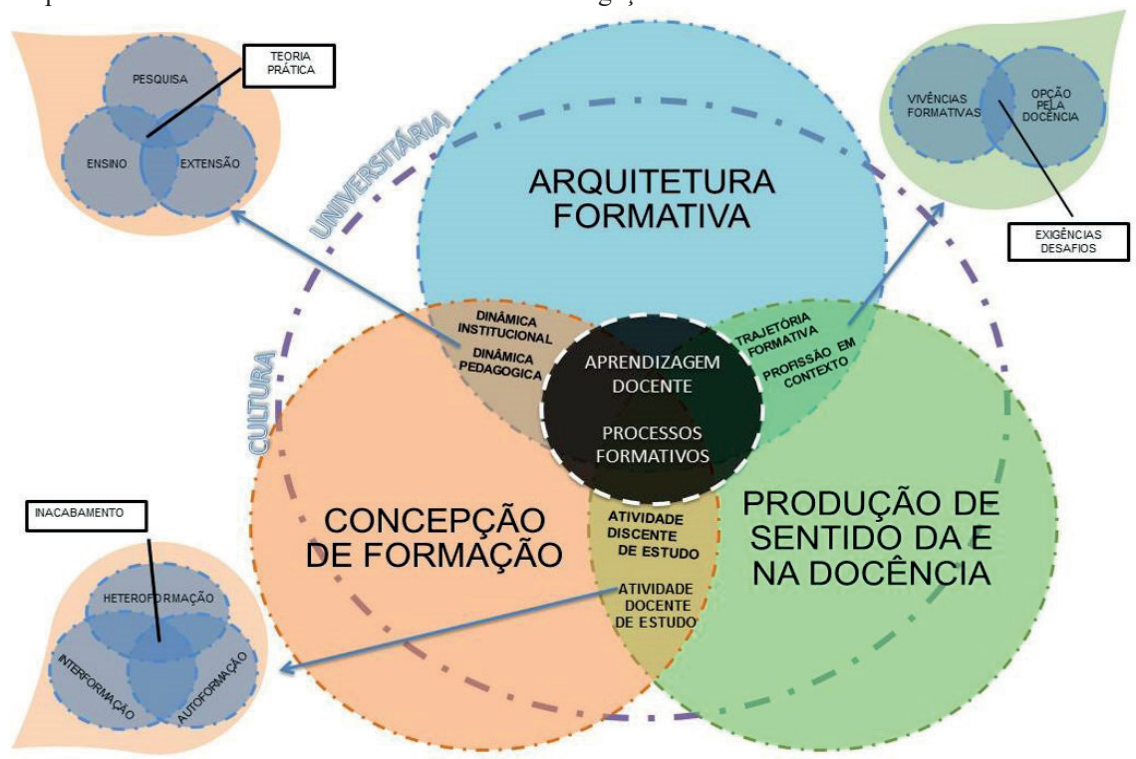

Fonte: os autores.

As categorias basilares de nosso estudo são aprendizagem docente e processos formativos. A aprendizagem docente revela que o processo de tomada de consciência que os sujeitos em processo de profissionalização produzem para aprender e ensinar é constitutivo do se tornar professor. As narrativas docentes e discentes, ao manifestarem suas concepções acerca da aprendizagem docente, assim expressam:

[...] eu acho que [aprender e ensinar] eles estão interligados, se tu consegues ensinar bem, a criança consegue aprender. Tem uma mão dupla entre o ensinar e o aprender, tens que te esforçar, tens que dar o teu melhor, várias formas, estratégias para ti conseguir fazer com que aquele aluno consiga aprender. $\mathrm{Na}$ verdade, a maioria dos alunos que chega para nós eles não aprendem pela via direta, a gente tem que achar caminhos indiretos para aquele aluno aprender, então esse é o nosso desafio, ensinar ele a aprender. Eu acho que é bem desafiador isso. (Marta, Formação Inicial, EE, IESP).

$\mathrm{Eu}$ acho que a gente aprende a ser professor sendo professor! Não existe outra forma de aprender. Eu acho que a Universidade dá uma base legal de conhecimento e não muito mais do que legal, uma base. Mas eu vejo, pela minha experiência e de tantos outros e de tantas pesquisas que tem, a gente vê que a Universidade, e não é esta Universidade, no modo geral a for- 
mação de graduação em licenciatura, ela dá uma base de conhecimento, assim, básica e por mais que a gente tenha estágio, é estágio, e é pouco isso. O dia a dia da sala de aula é que faz com que a gente aprenda o que é ser professor, como ser professor, como melhorar, o que fazer, o que a gente pode repetir e que é uma boa prática e outras que diz: "Não, isso aqui realmente não dá" ou "Para essa turma não dá e para a outra serviu". (Maria Lúcia, Formadora, EE, noturno).

Ensinar e aprender é uma relação de troca, que o professor não está lá só para ensinar, ele está lá também para aprender. Então, ao mesmo tempo em que ele está ensinando o aluno, ele está aprendendo com ele coisas novas. É muita [...] Ensinar e aprender são competências, ao mesmo tempo tu tens que amar aquilo que tu estás ensinando, aprender com mente aberta também. Então mais é a troca mesmo, deixar o aluno, partir do básico e aos poucos ele vai aprimorando o conhecimento. (Maria Fernanda, Formação Inicial, PED, noturno, IESP).

[...] Ensinar é complicado, eu acho que não é ensinar, é estimular a pessoa a aprender. Porque eu acho assim, o grande papel do professor é mostrar o quanto é bom aprender [...] eu acho que passar isso para as pessoas, que aquilo que ele aprende é dele e ele vai colocar na caixinha que ele quiser lá dentro e que tudo se usa [...] (Maria Eduarda, Formação Inicial, EE, noturno, IESP). (BOLZAN, 2013-2015).

Destacamos a compreensão de inacabamento e a busca de uma continuidade formativa expressa pela tomada de consciência de que, nesse processo, se é ensinante e aprendente simultaneamente. Consideramos que, ao analisarmos como os estudantes professores em formação inicial ou os professores formadores aprendem, podemos compreender porque ensinam desta ou daquela maneira. O modo como pensam interfere diretamente nas suas proposições pedagógicas, apontando consequências significativas nas formas de intervenção. Os professores agem, frequentemente, de acordo com o que pensam. Logo, toda tecnologia ou inovação na prática pedagógica está forçosamente implicada nas ideias e motivações do professor, levando-nos a refletir sobre a importância do seu pensamento e da sua ação (BOLZAN, 2007).

Seus processos de pensamento estão permeados por teorias e crenças; porém, esse pensamento não é observável. No entanto, sua conduta produz efeitos observáveis nos estudantes com os quais trabalham, o que podemos verificar por meio de suas produções e procedimentos. Há uma relação direta entre a ação do professor formador e a conduta e o rendimento dos estudantes; professores em formação inicial, assim como os estudantes professores em formação inicial, influenciarão o modo como os estudantes da educação básica responderão às suas proposições de ensino. 
Consideramos que as trajetórias pessoais e profissionais são fatores definidores dos modos de atuação do professor formador, revelando suas concepções sobre o seu fazer pedagógico. O que os docentes discentes pensam sobre ensinar e aprender está relacionado às suas vivências e à sua formação profissional, o que exige que pensemos os processos formativos vivenciados pelos sujeitos, traduzidos pelos trajetos de formação, implicando os percursos estabelecidos para alcançar os objetivos para se produzir professor.

Compreender os processos que permeiam as escolhas profissionais implica analisarmos os elementos mobilizadores para a assunção da carreira do magistério, reconhecendo o modo como essa escolha vai sendo reafirmada e/ou negada ao longo dos trajetos de formação. Nessa direção, ao analisarmos os percursos docentes, identificamos a composição de dois grupos específicos: um grupo de jovens doutores com experiência breve na educação básica e outro grupo constituído por professores doutores com extensa experiência na educação básica e no ensino superior. No primeiro grupo evidenciamos um percurso autodirecionado ao magistério superior, estando a titulação de mestre e doutor como investimento para o ingresso na docência nesse nível de ensino.

As narrativas que seguem expressam esses elementos.

Tu sabes que eu não sei muito bem, mas eu acho que desde a minha época de graduação eu sabia que um dia eu ia dar aula na universidade assim, talvez tivesse isso já meio como uma meta de... Enfim e eu acho que aí eu construí um percurso para isso assim. [...] o próprio percurso formativo de ir para um Mestrado, de ir para um Doutorado tinha este fim que era de ter uma qualificação para depois prestar um concurso e ingressar na universidade. (Flavia, Formadora, EE, noturno, IESP).

[...] a minha formação é bastante específica assim, eu fiz a graduação em Educação Especial e desde a época da graduação eu tive muita inserção em pesquisa. Então, quando eu me formei que eu fui para as escolas especiais, o meu desejo era voltar para o Ensino Superior justamente para trabalhar com pesquisa, que sempre me atraiu muito. (Cristiane, Formadora, PED, diurno, IESP). (BOLZAN, 2013-2015).

Já os professores com extensa experiência na educação básica e no ensino superior manifestam o investimento nos cursos de mestrado e doutorado como uma experiência de formação mobilizada pelas necessidades oriundas do trabalho na 
educação básica, surgindo o magistério no ensino superior em decorrência de suas trajetórias profissionais.

Eu comecei a pensar na possibilidade de atuar no ensino superior quando finalizei o mestrado e percebi o doutorado como um caminho viável de formação. A gente começa a pensar nas condições de trabalho, no reconhecimento que existe pelo trabalho que tu realizas no ensino superior, que é bem diferente do que na educação básica e até mesmo pela pesquisa e pelo estudo, porque na escola tu não tens tempo para estudar, para investir na tua formação [...]; então, tu vais percebendo a possibilidade e começas a investir para isso. (Mariele, Formadora, PED, diurno, IESP). (BOLZAN, 2013-2015).

O ingresso na universidade pública revela-se atrelado às condições de estabilidade e do tempo para a pesquisa.

A opção por vir para a universidade pública é uma questão mais de estabilidade, dedicação exclusiva. Eu vivia em uma ciranda [...] eram muitas coisas ao mesmo tempo. Claro, que eu tinha a percepção de que migrar de uma universidade para outra eu não estaria livre de trabalho e de envolvimento profissional, entretanto eu poderia estar me dedicando mais a uma instância única. (Cristiane, Formadora, PED, diurno, IESP). (BOLZAN, 2013-2015).

Assim, os professores, ao se inserirem no contexto universitário, deparam-se com o desafio de conhecer os modos organizacionais desse lugar, evidenciando que o dilema dos professores está em contextualizar esses lócus de atuação docente, como observamos nas narrativas que seguem:

Em uma universidade pública, nós temos essas instâncias bem definidas, a pesquisa, o ensino e a extensão. Obviamente que elas se entrecruzam e não podemos trabalhar com gavetas, separadas, estanques, entretanto, nós temos, enquanto docentes, em qualquer departamento, centro, enfim, encargos didáticos, e esses encargos didáticos eles requerem um envolvimento específico com a docência. (Mariele, Formadora, PED, diurno).

Tu levas um tempo para conhecer esse trânsito da instituição; como é que as coisas funcionam e aí tu estás um pouco mais ambientado e aí tu vais, por exemplo, presta um credenciamento para a Pós-Graduação, que eu entrei agora, então é um outro desafio, são coisas que a gente vai meio que se colocando, são coisas que a gente vai se colocando como um desafio. (Flavia, Formadora, EE, noturno, IESP). (BOLZAN, 2013-2015). 
Consideramos a profissão em contexto como um processo inerente ao aprender a ser professor, caracterizando a compreensão paulatina acerca das exigências e desafios da profissão, exigindo uma reafirmação da escolha profissional diária a partir da produção de sentido sobre e na docência.

A produção de sentido da/na docência abrange os processos de significação acerca do ser professor em termos de exigências e desafios implicados na profissão, permitindo ao docente contextualizar o seu lócus de atuação e os compromissos a ele inerentes. Nessa direção, as vivências formativas expressam as singularidades dos processos de aprender e ensinar, podendo nos sinalizar o modo como a docência é significada e (re)significada ao longo das trajetórias de formação (BOLZAN, 2010, 2013).

Ao analisarmos a significação da docência pelos estudantes, inicialmente, identificamos os motivos acerca da escolha pelos cursos de formação, os quais foram: projeção a partir de professores referências da Educação Básica; continuidade dos estudos considerando a formação no magistério/curso normal em nível médio; pendor natural e/ou vocação; influência dos familiares para a continuidade dos estudos; turno de oferta do curso (noturno) e necessidade de certificação.

Já na opção pelos Cursos de Educação Especial, diurno ou noturno, evidenciamos o predomínio de justificativas relativas ao contato com o público da educação especial, seja na educação básica, seja em contextos familiares, bem como uma segunda opção formativa, que foi proporcionada em razão do ponto de corte ou mesmo pela existência de vagas remanescentes.

Nessa perspectiva, encontramos indícios de que a opção pela docência nem sempre é agregada, pelo menos inicialmente, a sentidos e significados do sujeito acerca da formação que os cursos oferecem, uma vez que não há evidência clara sobre o campo de atuação profissional e nem mesmo das demandas da profissão. A tomada de consciência acerca dos desafios impressos à profissão docente vai sendo paulatinamente construída a partir do modo como a arquitetura formativa é dinamizada, incidindo, dessa forma, sobre a produção de sentido e de significado acerca da profissão docente.

Consideramos que os processos de ensino e de aprendizagem vivenciados ao longo da formação, inicial ou continuada, tanto de professores formadores quanto de professores em formação inicial, constituem-se pelas vivências formativas, repercutindo no processo de produção de sentido sobre e na docência. Esse processo baliza crenças e concepções teóricas implícitas e explícitas que os docentes têm acerca do fazer pedagógico. A compreensão sobre essa relação pode sinalizar a maneira como 
os professores em formação inicial processam as informações e como compreendem as formas de intervenção didática, como marco de referência para sua prática, construindo seu conhecimento pedagógico. As narrativas expressam o que consideram em termos de desafios e exigências acerca do ser professor na formação inicial.

Tem que ter um conhecimento teórico para poder aliar à prática. Se tu não sabes não adianta ter amor no coração e chegar lá e não saber o que vai fazer. Então, tem que ter o conhecimento teórico. Tu tens que ter a teoria ali para ti saber por onde tu vais seguir, o que tu vais buscar, porque é muita coisa misturada, é tudo ao mesmo tempo. Então tu tens que ter um discernimento, eu não eu vou seguir essa linha, eu vou fazer isso porque eu acredito que isso dá certo. Eu acredito que isso funciona dessa maneira, desse jeito. Então, é muito conhecimento teórico assim para poder aliar à prática, para que as coisas funcionem. (Fabiane, Formação inicial, PED, noturno, IESP).

[...] aqui nós precisamos de professores que tenham prática realmente no campo da educação, no sentido de compreender que os processos formativos que ele conduz com seus estudantes são os processos formativos que os estudantes vão precisar empreender com seus alunos algum tempo depois. Muitas vezes isso não acontece; a gente tem professores de outras áreas inclusive que nem são do CE. Nós temos uma disciplina que se chama PED, de práticas pedagógicas, que os professores nem participam, professores que são das letras, da $E F$, nem participam da PED, e é uma disciplina integradora do que acontece ao longo do semestre com o estudante, importante que todos estejam ali, por quê? Depois é cobrado do pedagogo o trabalho interdisciplinar, que ele saiba integrar conhecimentos e que esses conhecimentos integrados formem um todo conciso na cabeça desse homem, e aqui a gente não consegue fazer isso, por uma falta de envolvimento desses professores com o projeto político do curso. (Marlon, Formador, PED, diurno, IESP). (BOLZAN, 2013-2015).

Acreditamos que a construção da docência é compartilhada, faz-se na prática em aula e no exercício da atuação cotidiana nos espaços pedagógicos e institucionais. É uma conquista social e compartilhada, pois implica trocas e representações, envolvendo ações autoformativas, ${ }^{44}$ heteroformativas ${ }^{55}$ e interformativas. ${ }^{66}$ Tais ações

\footnotetext{
${ }^{4}$ Ações autoformativas implicam atividades conscientemente escolhidas pelos docentes para qualificar seu crescimento pessoal e profissional que envolve peculiaridades da aprendizagem adulta e a vontade de se constituir como profissional em seu campo de atuação.

5 Ações heteroformativas se organizam e se desenvolvem por agentes externos, especialistas, sem envolvimento ou comprometimento dos professores. Em geral, não há implicação dos participantes com a proposta formativa em pauta.

${ }^{6}$ Ações interformativas caracterizam-se pela busca de atividades conjuntas, em um sistema de cooperação. Há um evidente empenho por parte dos sujeitos de se desenvolverem e se aperfeiçoarem profissionalmente,
} 
ocorrem em consonância com a arquitetura formativa a que cada sujeito está submetido, considerando-se as definições institucionais de cada espaço e tempo de formação, bem como pela cultura universitária, elemento que permeia esse processo.

A arquitetura formativa caracteriza-se por um conjunto de elementos que perfazem um todo; a estrutura, a natureza, a dinâmica organizacional e pedagógica pensada e ofertada na/para formação, expressa pelo desenho professoral que se pretende alcançar em consonância com a performance a ser empreendida ao longo desse processo, inicial, continuado ou permanente.

O conceito de arquitetura formativa toma o ser humano como centro, considerando que tudo que se faz presente adquire significado, sentido e valor por constituir-se um mundo humano. Logo, a arquitetura descreve as relações de atividade humana, entendida como atividade responsiva, de viver o mundo situado e localizado espacial e temporalmente e, portanto, permeado por valores, afirmações e ações reais, composto por pessoas reais, vinculadas entre si por situações concretas, pois [...] sean cuales fueren ellas, condiciones y formas en que transcurre la actividad del hombre, cualquiera que sea la estructura que elija, no se puede considerar como desgajada de las relaciones sociales, de la vida de la sociedade." (LEONTIEV, 1984, p. 67). ${ }^{77}$

Nessa direção, a arquitetura formativa revela as dimensões institucionais e pedagógicas, balizadas pelas articulações produzidas via tríade ensino, pesquisa e extensão. Tais dinâmicas expressam as fragilidades e potencialidades formativas que são a base desse desenho e são produzidas em determinado contexto histórico, social e cultural, evidenciando que as relações teórico-práticas que movimentam a arquitetura formativa são tensionadas pela cultura universitária, a qual “[...] compreende um conjunto de representações, ideias, valores, tempos e espaços de desenvolvimento profissional vivenciados pelos sujeitos em formação, configuradas em um lócus sociocultural específico, envolvendo as diferentes áreas do conhecimento." (BOLZAN, 2008, p. 118).

Ao analisarmos as inserções dos acadêmicos nas atividades de extensão e as ações de inserção no campo da educação, dos 35 acadêmicos entrevistados, 21 atuam e/ou já atuaram em atividades escolares como professor, estagiário ou como bolsista no Programa de Iniciação à Docência (PIBID). Os acadêmicos dos Cursos de Educação Especial expressam que sua inserção no contexto escolar é menor do que a

implica um trabalho coletivo e grupal, centrado em interesses e necessidades comuns, indicando a cultura institucional como mote para esse processo.

7 Tradução nossa: [...] sejam quais forem as condições e formas que transcorrem a atividade do homem, qualquer que seja a estrutura que escolha, não se pode considerar como desvinculada das relações sociais, da vida em sociedade 
dos estudantes dos Cursos de Pedagogia, uma vez que as atividades de inserção ocorrem predominantemente em estágios curriculares previstos ao longo das matrizes.

Nos Cursos de Pedagogia identificamos que há um número superior a 58\% dos entrevistados que estão vinculados à atuação no contexto escolar, estando o PIBID em destaque nas duas instituições. Os demais estudantes entrevistados, do Curso, relataram não estarem vinculados aos contextos escolarizados. Já nos Cursos de Educação Especial essa situação se altera, pois 54\% dos estudantes relataram não terem vinculação ao campo educacional. Dos estudantes $46 \%$ realizam ou realizaram atividades, seja como bolsistas do PIBID, seja como estagiários no contexto escolar.

No que se refere ao envolvimento na pesquisa e/ou extensão no percurso formativo dos estudantes dos Cursos de Pedagogia, a participação em pesquisa prepondera sobre a extensão, ou seja, mais de 50\% dos estudantes participam ou estão vinculados a um grupo de pesquisa.

Já nos Cursos de Educação Especial essa participação se manifesta de forma inversa, ou seja, mais de $60 \%$ dos estudantes não participa de atividades de pesquisa ou de extensão, atuando mais especificamente em situações de atendimentos individuais ou atividades de estágio.

Nessa direção, as narrativas discentes expressam que o envolvimento em atividades de pesquisa e extensão é um diferencial na formação, indicando que essa possibilidade não apenas amplia os horizontes da profissão como caracteriza um processo formativo tão importante quanto a frequência às atividades disciplinares ofertadas pelos cursos. Contudo, não são todos os acadêmicos envolvidos com o conjunto de ofertas que dinamizam a arquitetura dos cursos investigados, exigindo que pensemos sobre a concepção de formação que permeia o se tornar professor.

Os professores formadores em suas narrativas demonstram preocupação com o perfil aprendente dos acadêmicos em formação, denotando o desafio de mobilizá-los em seus trajetos formativos.

Tais aspectos estão expressos nas narrativas que seguem:

Eu vejo que a gente tem muitos desafios, no campo da Educação Especial. Isso se agrava um pouquinho mais, eu acho que na Pedagogia também, porque, às vezes, não é a primeira opção, com frequência não é a primeira opção de curso. $\mathrm{O}$ cara já tentou Educação Física, Fisioterapia, Fonoaudiologia, Enfermagem e aí chega aqui porque foi muitas vezes o que restou e a gente tem altos índices [...] se a gente pergunta para a turma quem fez porque quis, em geral é um número pequeno. Eu já me convenci assim que tu podes entrar aqui sem saber por que tu chegaste, mas tu não podes sair sem saber o que tu estás fazendo aqui, porque a grande maioria deles chega na Educação 
Especial sem ser uma escolha e eu acho que isso é um ponto muito importante. E aí claro, isso vai ter efeitos na forma como os alunos se relacionam com o curso. (Flavia, Formadora, EE, diurno, IESP).

O que seria mais importante é começar a pensar algumas atividades que trabalhassem essa questão da sensibilização e conscientização de que nós escolhemos uma profissão, e não sei o quanto isso é trabalhado, principalmente, nos primeiros semestres. Eu trabalho, normalmente, nos últimos anos, no $6^{\circ}$ semestre, na véspera do estágio, e confesso que me apavoro um pouco. Eu não sou de cobrar e de fazer provas e testes, mas rodo a baiana, às vezes, pela irresponsabilidade que eu vejo em pedagogas quase formadas, é impossível aceitar que as pessoas se portem sem interesse diante daquilo que a gente propõe. Uma leitura mais séria, um debate mais aprofundado, tanto que às vezes eu pergunto: "Vocês, semestre que vem, estão indo para estágio. Eu pergunto para cada uma de vocês: em quais ou em qual das colegas você confiaria um filho seu para ser educado por essa pessoa, ou você confiaria o seu próprio filho a você mesmo?" Dada a seriedade com que você assumiu o seu preparo profissional. [...] (Paulo, Formador, PED, diurno, IESP). (BOLZAN, 2013-2015).

Nessa direção, um dos desafios impressos ao formador é a promoção da tomada de consciência acerca da dimensão autoformativa envolvida no aprender a ser professor, remetendo-nos às escolhas conscientemente dirigidas e reavaliadas pelo sujeito.

Logo, ao enfatizarmos as concepções de formação docente, aqui entendidas como o conjunto de ideias e valores compreendidos pelos sujeitos acerca do tornar-se professor, destacamos a compreensão de um processo que abarca aprendizagens diversas, envolvendo dimensões intra e interpessoais associadas aos contextos socioculturais nos quais os sujeitos se encontram. O contexto experiencial é demarcador das vivências formativas construídas e consolidadas ao longo dos percursos pessoal e profissional (BOLZAN, 2010, 2013; BEILLEROT, 2006).

Nessa dimensão, as atividades discentes de estudo e as atividades docentes de estudo caracterizadas por ações de hetero, inter e autoformação indicam como ponto de intersecção o inacabamento, elemento destacado pelos sujeitos ao narrarem suas ideias.

O Educador Especial é uma pessoa que tem que estar sempre aprendendo; toda hora tá chegando coisas novas. Tu sais formado daqui, mas tudo aquilo que eu aprendi vai ser uma base só, então eu tenho que... [pausa] Eu vou me formar, vou sair daqui e tenho que estudar mais um pouco, porque na verdade 
o meu curso ele dá ênfase em três áreas só, o resto fica desfalcado. Tem ênfase em dificuldade de aprendizagem, deficiência mental e surdez, então, autismo, outras síndromes, a gente tem que correr atrás. (Marta, Formação Inicial, EE, diurno, IESP).

Formação para mim ela é uma continuidade. Eu estou na minha formação inicial como professora. Eu vejo que a graduação é uma formação inicial, e então eu pretendo fazer uma especialização, estar sempre estudando. Vejo que a formação é uma continuação. (Gisa, Formação Inicial, PED, noturno, IESP).

[...] a gente sabe que, se tratando de docência, a gente nunca está pronta, não tem como estar pronto porque não tem uma receita que você diga assim: "Não, isso vai funcionar para qualquer turma que eu pegue!" Não, uma turma é diferente da outra, os alunos são diferentes, com uma turma é muito tranquilo, com a outra é um caos; com uma você enfrenta desafios diferentes, sabe a própria docência é um grande desafio. (Malvina, Formadora, PED, diurno, IESP).

Eu acho que eu preciso aprender que eu não vou ter todas as respostas, até porque eu não aprendi tudo. $\mathrm{O}$ que eu gostaria mais, talvez, nesse momento eu não estou conseguindo fazer, mas eu quero ver se posteriormente eu consiga, assim, é voltar a estudar mais [...] Eu preciso retomar coisas mais... Estudar um autor, eu quero estudar Skinner, estudar Emília Ferreiro, eu quero estudar... Essas coisas que me, que nesse momento, assim, me desafiam mais. Nesse momento agora, eu não estou tendo possibilidade de fazer. (Eugênia, Formadora, EE, noturno, IESP). (BOLZAN, 2013-2015).

Ao destacarmos o conjunto de elementos que compõem as dimensões de análise decorrentes das categorias aprendizagem docente e processos formativos, ressaltamos a não linearidade desse processo. O estudo empreendido para compreender a implicação entre as concepções de aprender a docência e os processos formativos em desenvolvimento nos permitiu evidenciar pontos de intersecção que compõem a dinâmica processual, expressa pelas exigências e desafios da docência e pela tomada de consciência do inacabamento. Observamos a cultura universitária como elemento que permeia a dinamização e a organização da arquitetura formativa, configurando e reconfigurando as concepções de formação, de modo a produzir diferentes sentidos na e sobre a docência.

O recorte apresentado permite-nos indicar os elementos que emergiram das reflexões iniciais sobre as narrativas mapeadas, configurando-se indicadores importantes dos processos formativos implicados na aprendizagem de ser professor. Entretanto, ressaltamos o caráter preliminar dos achados aqui destacados. 


\section{FORMAÇÃO PERMANENTE E DESENVOLVIMENTO PROFISSIONAL DOCENTE: DESAFIOS NAS LICENCIATURAS}

Nossos estudos indicam alguns princípios para a formação dos formadores e para a formação inicial, pois como sujeito em formação permanente é necessário que se considere a complexidade de tais processos. Observamos que os processos estão compostos por fases claramente diferenciadas por seu conteúdo curricular, havendo necessidade de integrar-se aos processos de mudança, de inovação e de desenvolvimento das matrizes formativas; de estabelecer uma evidente conexão entre os processos de formação profissional com os processos de desenvolvimento institucional (escola, universidade, comunidade); e de articulação e integração entre a formação e os conteúdos acadêmicos, disciplinares e da formação pedagógica necessários à constituição do trabalho docente.

Nesse sentido, destacamos o conhecimento pedagógico e o conhecimento dos conteúdos como fundamentais para a estruturação do pensamento pedagógico do professor, sendo indispensável à integração teórico-prática. Para que a prática seja fonte de conhecimento e se constitua em epistemologia é essencial que o professor reflita sobre a própria ação, possibilitando, assim, a (trans)formação. É essencial que o professor busque a relação entre a formação profissional recebida e o tipo de educação que desenvolverá, considerando-se a individualização de cada profissional, pois ensinar e aprender pressupõe caminhos próprios, que dependem das experiências de ser professor e dos seus conhecimentos pessoais, além de suas necessidades e interesses, permitindo, assim, que possa se adaptar ao contexto no qual atuará, fomentando sua participação e reflexão e, por fim, possibilitando questionar as crenças que manifesta e as práticas institucionais que desenvolve.

Podemos afirmar que a formação de professores é um processo que tem de manter princípios éticos, didáticos e pedagógicos comuns, independentemente do nível de formação em questão. É preciso criar uma rede de relações capaz de proporcionar que o conhecimento seja compartilhado e reconstruído cotidianamente, desde a formação inicial. Para que se tenha sucesso na formação de professores é essencial a criação de políticas orgânicas, com sustentação no tempo, considerando-se a diversidade de elementos que interferem na complexa atividade de ensinar e aprender (VAILLANT; MARCELO, 2012). 
Nessa direção, indicamos que os processos de interação e mediação se constituem à medida que os instrumentos culturais, como discurso e atividade intelectual reflexiva sobre os saberes práticos docentes, desenvolvem-se.

Dessa forma, as narrativas coletadas nos permitem destacar que, no transcurso das interações formativas, há o compartilhamento de significados e ideias sobre o conhecimento específico da área de atuação e o conhecimento pedagógico dos formadores e dos professores em formação inicial.

Ao voltarmos nossa atenção para as narrativas dos colaboradores deste estudo, somos capazes de compreender o cenário onde se estabelecem os múltiplos diálogos e, consequentemente, os significados que as palavras tomaram na tessitura dessa rede de relações. Os acontecimentos e fatos narrados, fundamentais à tessitura dessa rede, apontam para a importância da troca e do compartilhamento nos espaços formativos.

A tessitura dessa rede nem sempre é marcada pela solidariedade e pelo despojamento dos participantes. A objetivação de ideias expressas pelos docentes em formação inicial ou pelos docentes formadores, ao trazerem suas narrativas, enceta a relevância desses elementos fundamentais à construção compartilhada. Assim, a partir da constituição dessa rede, podemos observar que a construção da docência pode ser favorecida, considerando-se que sua organização possa acontecer por meio de um trabalho coletivo e sistemático, ou seja, de forma compartilhada.

Portanto, o processo de construção da rede pode ser pensado a partir de dois pontos principais. O primeiro deles é o contraste entre diferentes pontos de vista dentro de uma atividade que exige colaboratividade dos participantes, de maneira que a tarefa conjunta se realize a partir da reorganização dos pontos de vista, muitas vezes, divergentes. O segundo ponto é a multiplicidade de formas de regulação mútua por meio da linguagem, possibilitando essa rede de interações. Esses processos podem ser caracterizados pela possibilidade de utilizar a comunicação entre os sujeitos como guia ou regulador das próprias ações, pela utilização da própria linguagem, para guiar e regular as ações dos pares, além da possibilidade de usar a própria linguagem para guiar as próprias ações; nesse sentido, a assimetria de papéis pode levar à assimetria da participação, o que precisa ser cuidadosamente observado durante as atividades desenvolvidas (BOLZAN, 2002).

É, ainda, importante referir que a produção de espaços interativos precisa ser cuidadosamente pensada e organizada, de maneira que todos os sujeitos desse processo possam usufruir, realmente, de suas potencialidades, explorando suas ideias e pontos de vista. Nesse sentido, a interação pode ser usada como um meio de tornar 
acessível o desenvolvimento das capacidades cognitivas, de equilíbrio pessoal, de relação interpessoal e de atuação em diferentes espaços sociais, mas, para que isso aconteça, é essencial que se organizem e se proponham atividades, orientações e materiais de apoio durante todo o processo formativo.

O êxito nas atividades de formação pressupõe pensar nas condições de trabalho do professor, na organização e no desenvolvimento de pesquisas centradas na dinâmica do trabalho pedagógico, bem como a possibilidade de articular as áreas de conhecimento, aproximando elementos teórico-práticos de modo a fortalecer as redes de conhecimentos.

Assim, considerando as reflexões realizadas, podemos dizer que: o processo de tornar-se professor é longo e complexo, exigindo muitas horas de observação, além da construção de condições para o enfrentamento dos desafios da docência, como trabalhar com as dúvidas, incertezas, ansiedade e solidão pedagógica; a análise de situações de ensino por meio do compartilhamento de pontos de vista comuns ou divergentes favorece a metarreflexão e, consequentemente, a aprendizagem docente; a relação assimétrica entre professores formadores e professores em formação inicial representa uma relação formativa e colaboradora, na qual os participantes, mesmo partindo de pontos de vista distintos ou até mesmo divergentes, estabelecem, durante as discussões, posições intersubjetivas, num contexto de negociação que tende à construção conjunta de "novos" sentidos e significados para as situações de ensino, seja na educação básica, seja na aula universitária; o estabelecimento de intercâmbios entre professores formadores e professores em formação inicial é capaz de promover avanços na direção da (trans)formação do fazer pedagógico tanto na aula universitária quanto na educação básica; as atividades compartilhadas possibilitam o surgimento de novas perspectivas de análise de situações de ensino, provocando a ampliação do foco de estudo e, consequentemente, possibilitam a reorganização das estratégias do trabalho pedagógico tanto na educação básica quanto na educação superior; o saber como fazer é necessário, mas não suficiente quando ingressamos no contexto profissional; é essencial que o professor saiba por que e quando realizar determinada ação; a participação em grupos de estudos e pesquisa evidencia que o apoio e o compartilhamento entre os participantes geram a possibilidade de transformação e de construção do "novo" na formação docente e no seu desenvolvimento profissional.

Logo, um dos mais importantes elementos da formação docente e do desenvolvimento profissional ocorre na direção da consideração das atividades de ensino, pesquisa e extensão como atividades essenciais aos processos formativos, pois pode- 
rão ser mobilizadoras da reflexão do professor, possibilitando-se que esses sujeitos se tornem capazes de aprender mediante suas vivências e de gerar novos conhecimentos.

Desse modo, é possível examinar como interesses manifestos e potenciais podem se constituir em interrogantes capazes de provocar o aprofundamento e a busca da compreensão sobre questões como: as relações entre a experiência prática e as proposições pedagógicas na formação docente, entre as experiências intrapessoais e a aprendizagem docente, bem como a criação de equipes de trabalho e a possibilidade de (trans)formação e construção do "novo" nas instituições universitárias, entre a reflexão e a apropriação de novos saberes profissionais docentes nos processos de formação de professores e no desenvolvimento profissional docente, entre tantas outras (BOLZAN, 2009).

O que, sobretudo, parece-nos valioso dizer é que o movimento de produção que realizamos é capaz de se inscrever em um processo mobilizador das forças reflexivas acerca do aprender a ser professor, seja ele um professor formador, seja um estudante professor em formação inicial, e, por conseguinte, transformar seus processos formativos em atividades coletivas, compartilhadas e solidárias.

\section{REFERÊNCIAS}

BAKHTIN, M. Estética da criação verbal. Tradução Paulo Bezerra. 5. ed. São Paulo: Martins Fontes, 2010a.

BAKHTIN, M. Para uma filosofia do ato responsável. Tradução Valdemir Miotello e Carlos Alberto Faraco. São Carlos: Pedro \& João, 2010b.

BAKHTIN, M. (Volochinov). Marxismo e filosofia da linguagem. Problemas fundamentais do método sociológico na ciência da linguagem. Tradução Michel Lahud et al. 7. ed. São Paulo: HUCITEC, 1995.

BEILLEROT, J. La formación de formadores: entre la teoria y la práctica. 1. ed. Buenos Aires: Centro de Publicaciónes Educativas y material didáctico, 2006.

BOLZAN, D. P. V. Aprendizagem da Docência: processos formativos de estudantes e formadores da educação superior. Relatórios Parciais de Pesquisa, Bolsa Pq CNPq, registro ${ }^{\circ}$ 032835, GAP/CE/UFSM, 2013, 2014.

BOLZAN, D. P. V. Aprendizagem docente e processos formativos: novas perspectivas para educação básica e superior. Relatório Final de Pesquisa, registro $\mathrm{n}^{\mathrm{o}}$ 020117, GAP, CNPq/PPGE/CE/UFSM, 2009a. 
BOLZAN, D. P. V. Aprendizagem docente e processos formativos: movimentos construtivos da professoralidade na educação básica e superior. Relatórios de Pesquisa, Bolsa PQ 10/2009, registro n 304863, GAP/CE/UFSM, 2010, 2011, 2012a.

BOLZAN, D. P. V. Aprendizagem docente: movimentos da professoralidade no ensino superior. In: PULLIN, E. M. M. P.; BERBEL, N. A. N. (Org.). Pesquisas em Educação: inquietações e desafios. Londrina: EDUEL, 2012b.

BOLZAN, D. P. V. Formação de professores: compartilhando e reconstruindo conhecimentos. 1. ed. Porto Alegre: Mediação, 2002.

BOLZAN, D. P. V. Formação Permanente e conhecimento pedagógico compartilhado: possibilidades na docência universitária. In: ISAIA, S. D. P. V. M.; A. BOLZAN, D. P. V.; MACIEL, A. M. R. (Org.). Pedagogia universitária: tecendo redes sobre a educação superior. Santa Maria: Ed. UFSM, 2009b. p. 163-176.

\section{BOLZAN, D. P. V. Grupo de discussão para organização da análise categorial} do projeto de pesquisa Aprendizagem da Docência: processos formativos de estudantes e formadores da educação superior. jan./fev. 2015.

BOLZAN, D. P. V.; ISAIA, S. Aprendizagem docente na educação superior: construções tessituras da Professoralidade. Revista Educação, Porto Alegre: EDIPUCRS, 2006.

BOLZAN, D. P. V.; ISAIA, S. M. de A. O conhecimento pedagógico compartilhado e a aprendizagem docente: elementos constituintes dos processos formativos na educação superior. Revista digital Políticas Educativas, v. 1, p. 69-79, 2007.

BOLZAN, D. P. V.; ISAIA, S. M. de A. Pedagogia universitária e aprendizagem docente: relações e novos sentidos da professoralidade. Revista Diálogo Educacional, v. 10, p. 13-26, 2010.

BOLZAN, D. P. V. Pedagogia Universitária e processos formativos: a construção de conhecimento pedagógico compartilhado. In: EGGERT, E. et al. (Org.). Trajetórias e processos de ensinar e aprender: didática e formação de professores. 1. ed. Porto Alegre: EDIPUCRS, 2008. v. 1.

CUNHA, M. I. Docência na universidade, cultura e avaliação institucional: saberes silenciados em questão. Revista Brasileira de Educação, Rio de Janeiro, v. 11, n. 32, maio/ago. 2006.

CLANDININ, D. J.; CONNELLY, F. M. Relatos de experiencia y investigación narrativa. In: LARROSA, J. et al. (Org.). Déjame que te cuente: ensaios sobre narrativa y educación. Barcelona: Laertes Ediciones, 1995. 
DA ROCHA, A. M. R. A [re]construção da docência superior nas interconexões entre ambientes formativos presenciais e virtuais. Projeto de Pesquisa n. 0333451, GAP/CE/UFSM, 2013-2015.

ISAIA, S. M. de A. Os movimentos da docência superior: especificidades nas diferentes áreas de conhecimento e sua influência na atuação docente. Projeto de Pesquisa Pq/CNPq n. 034589, GAP/CE/UFSM, 2012-2015.

ISAIA, S. M. da A. Verbetes. In: MOROSINI, M. (Org.). Enciclopédia de Pedagogia Universitária: Glossário. Brasília, DF: INEP/RIES, 2006. v. 2.

LEONTIEV, A. N. Actividad, conciencia y personalidad. Editorial Cartago de México, S.A. Cerrada de San Antonio No 22, 1984.

MARCELO, G. C. Formación del profesorado para el cambio educativo. Barcelona: Ediciones Universitarias de Barcelona, 1999.

SACRISTÁN, G. Docencia y cultura escolar: reformas e modelo educativo. 2. ed. Buenos Aires, 1997.

SARMENTO, M. A vez e a voz dos professores: contributo para o estudo da cultura organizacional da escola primária. Portugal: Porto Editora LDA, 1994.

POWACZUK, A. C. H. A tessitura da docência universitária de professores iniciantes: movimentos da professoralidade. Projeto de Estágio Pós-Doutoral. PPGE/CE/ UFSM, 2014.

VAILLANT, D.; MARCELO, C. Ensinando a ensinar: as quatro etapas de uma aprendizagem. Curitiba: Ed. UTFPR, 2012.

VYGOTSKI, L. S. Obras Escogidas. Madrid: Visor: Distribuciones, 1991.

ZABALZA, M. A. O ensino universitário: seu cenário e seus protagonistas. Porto Alegre: Artmed, 2004.

Recebido em: 09 de agosto de 2016

Aceito em: 29 de dezembro de 2016

Endereço para correspondência: Rua Padre Gabriel Bolzan, 1777, Alameda A, casa 89, Bairro São José, 97095-500, Santa Maria, Rio Grande do Sul, Brasil; dbolzan19@gmail.com 